\title{
Município, poder local e planos municipais de educação
}

\author{
Municipality, local power and municipal education plans
}

\section{Planes de municipio, poder local y educación municipal}

\author{
Marli dos Santos de Oliveira* \\ ORCID: https://orcid.org/0000-0003-1440-9045 \\ Maria Dilneia Espindola Fernandes** \\ ORCID: https://orcid.org/0000-0001-5218-8541 \\ Elisangela Alves da Silva Scaff ${ }^{* * *}$ \\ ORCID: https://orcid.org/0000-0002-7682-0879
}

\begin{abstract}
Resumo: As discussões acerca do planejamento educacional em geral e, em âmbito municipal em particular, exigem novas reflexões a fim de situar a materialização da autonomia municipal, sobretudo no que concerne à sua política educacional tendo como epicentro seu respectivo plano municipal de educação. O presente texto tem por objetivo contextualizar o município enquanto ente federativo situando tal status jurídico-normativo à materialização da sua autonomia em matéria educacional, a partir das discussões de poder local e plano municipal de educação. Metodologicamente, a pesquisa constitui-se bibliográfica e documental na medida em que se busca a compreensão da produção do conhecimento científico acerca de determinados recortes da realidade investigada. O reconhecimento do município como ente federativo requer novas aproximações acerca do papel das instâncias e sujeitos locais, sobretudo com o advento da legislação educacional posterior à promulgação da Constituição da República Federativa do Brasil de 1988, que delimita o papel do poder local em matéria educacional.
\end{abstract}

Palavras-chave: Planejamento educacional. Educação Municipal. Planos Municipais de Educação.

\begin{abstract}
Discussions about educational planning in general and, at the municipal level in particular, require new reflections in order to situate the materialization of municipal autonomy, especially with regard to its educational policy having its respective municipal education plan as its epicenter. This text aims to contextualize the municipality as a federative entity, placing such legal-normative status to the materialization of its autonomy in educational matters, based on discussions of local power and the municipal education plan. Methodologically, the research constitutes bibliographic and documentary insofar as it seeks to understand the production of scientific knowledge about certain aspects of the investigated reality. The recognition of the municipality as a federative entity requires new approaches to the role of local bodies and individuals, especially with the advent of educational legislation after the promulgation of the 1988 Constitution, which delimits the role of local power in educational matters.
\end{abstract}

Keywords: Educational planning. Municipal Education. Municipal Education Plans.

\footnotetext{
* Doutora em Educação pela Universidade Federal de Mato Grosso do Sul. Pedagoga no Instituto Federal de Educação, Ciência e Tecnologia de Mato Grosso do Sul (Brasil), no Núcleo de Gestão Administrativa e Educacional (NUGED) Campus Ponta Porã I. E-mail: marli.oliveira@hotmail.com.

** Doutora em Educação pela Unicamp, com estágio de Pós-Doutorado pela Faculdade de Educação da Universidade de São Paulo. Professora Titular da Universidade Federal de Mato Grosso do Sul. Professora Visitante credenciada no Programa de Pós-Graduação em Educação da Universidade Federal de Mato Grosso do Sul. Bolsista produtividade CNPq. E-mail:mdilneia@uol.com.br

*** Doutora em Educação pela USP, com pós-doutoramento pela mesma instituição. Professora Associada da Universidade Federal do Paraná, no Programa de Pós-Graduação em Educação. Integra o Núcleo de Políticas Educacionais (NUPE) e é coordenadora da Rede de Estudos e Pesquisas em Planejamento e Gestão Educacional (REPLAG). E-mail: eliscaff@ gmail.com
} 
Município, poder local e planos municipais de educação...

Resumen: Las discusiones sobre la planificación educativa en general y, a nivel municipal en particular, requieren nuevas reflexiones para ubicar la materialización de la autonomía municipal, especialmente en lo que se refiere a su política educativa que tiene como epicentro su respectivo plan de educación municipal. Este texto tiene como objetivo contextualizar el municipio como entidad federativa, situando tal estatus jurídico-normativo a la materialización de su autonomía en materia educativa, a partir de discusiones sobre el poder local y el plan educativo municipal. Metodológicamente, la investigación se constituye bibliográfica y documental en la medida en que busca comprender la producción de conocimiento científico sobre determinados aspectos de la realidad investigada. El reconocimiento del municipio como entidad federativa requiere nuevos enfoques del papel de los entes locales y de las personas, especialmente con el advenimiento de la legislación educativa tras la promulgación de la Constitución de 1988, que delimita el papel del poder local en materia educativa. Palabras clave: Planificación educativa. Educación Municipal. Planes de Educación Municipal.

\section{INTRODUÇÃO}

As análises concernentes ao planejamento da educação municipal no contexto dos planos decenais de educação requerem a contextualização dos antecedentes históricos, jurídicos e políticos que auferiram ao contexto local novos contornos sociais. A promulgação da Constituição da República Federativa do Brasil de 1988 (CRFB/1988), dentre outras garantias, assegurou aos municípios brasileiros o status de ente federativo, cuja República Federativa brasileira advém da união indissolúvel da União, Estados e Municípios, todos autônomos, nos termos do art. 18 da CRFB/1988.

Nesse contexto, as discussões acerca do planejamento educacional em geral e, em âmbito municipal em particular, exigem novas reflexões a fim de situar a materialização da autonomia municipal, sobretudo no que concerne à sua política educacional tendo como epicentro seu respectivo plano municipal de educação.

Desse modo, a fim de compreender tais fenômenos educativos e contribuir para as discussões relacionadas o presente texto tem por objetivo contextualizar o município enquanto ente federativo situando tal status jurídico-normativo à materialização da sua autonomia em matéria educacional, a partir das discussões de poder local e plano municipal de educação.

Metodologicamente, a pesquisa constitui-se bibliográfica e documental na medida em que se busca a compreensão da produção do conhecimento científico acerca de determinados recortes da realidade investigada. Cumpre registrar que os documentos são atividades humanas que revelam suas ideias, opiniões e formas de atuação e percepção de mundo, a parir de documentos escritos, numéricos, estatísticos, visuais, dentre outros (BRAVO, 1991). Embora a pesquisa documental possibilite uma multiplicidade de aportes, na presente investigação destaca-se os documentos escritos, oriundos predominante do governo federal, cuja análise será realizada a partir da literatura atinente ao tema, notadamente os relacionados ao federalismo, poder local e planejamento educacional.

O momento atual, com as intermitências político-governamentais na política educacional, sinaliza e reafirma a necessidade de compreensão dos fenômenos educativos, sobretudo quando ameaçados os espaços, instituições e legislações relacionadas à democracia brasileira. Discutir, portanto, os desafios relacionados aos espaços, à autonomia e a educação municipal pode contribuir no enfrentamento aos 
desmontes sociais, predominantemente no bojo das políticas sociais em geral e, em particular, das políticas de plane- jamento educacional.

\section{O MUNICÍPIO NA CRFB/1988 E O PODER LOCAL}

Ao tratar do federalismo, fala-se de um tipo especifico de Estado, dentre os muitos que possam existir. "Federação provém do latim: foederatio que, por sua vez, resulta do latim foedus. Foeduseris significa contrato, aliança, união, ato de unir-se por aliança. Significa também se fiar, confiar-se, acreditar" (CURY, 2006, p. 114). No federalismo têm-se um Estado Soberano com unidades federadas subnacionais que gozam de autonomia dentro dos limites jurisdicionais específicos e atribuídos.

No regime federativo os poderes de governo repartem-se entre as instâncias governamentais tendo em vista as competências legalmente definidas. Essa repartição de com- petências é elemento fundamental para elucidar a forma federativa de Estado. Cury (2006, p.115) distingue três tipos de federalismo, quais sejam:

1- O federalismo centrípeto se inclina ao fortalecimento do poder da União, em que, na relação concentração/difusão do poder, predominam relações de subordinação dentro do Estado Federal [...].

2- O federalismo centrífugo se remete ao fortalecimento do poder do Estadomembro sobre a União, em que, na relação concentração/difusão do poder, prevalecem relações de larga autonomia dos Estados membros [...]

3- O federalismo de cooperação busca um equilíbrio de poderes entre a União e os Estados membros, estabelecendo laços de colaboração na distribuição das múltiplas competências por meio de atividades planejadas e articuladas entre si objetivando fins comuns [...] (CURY, 2006, p.115 grifos do autor).

Historicamente, o Brasil percorreu esses três tipos de federalismo desde a sua instituição legal por meio do Decreto no 01 de 1889. Na Velha República, especialmente entre os anos de 1898- 1930 tivera-se o federalismo centrífugo. Entre os anos de 1930 e 1980, embora com algumas diferenciações para períodos específicos, como o de 19461964, vigorou o federalismo centrípeto. O federalismo de cooperação passa a vigorar a partir do registro jurídico da CRFB/1988.

O caráter nacional de um Estado Federativo está concentrado em um polo central de poder, difundindo-se, ao mesmo tempo, a autonomia nacional de um Estado-Nação e a autonomia de seus membros. A promulgação da CRFB/1988 recusou tanto um federalismo centrífugo como centrípeto, optando pelo federalismo cooperativo sob a denominação de "regime de colaboração recíproca, descentralizado, com funções compartilhadas entre os entes federativos" (CURY, 2006 p. 121).

A CRFB/1988 foi apresenta em seu Art. 1 que "A República Federativa do Brasil, formada pela união indissolúvel dos Estados e Municípios e do Distrito Federal, constitui-se em Estado Democrático de Direito [...]". Em seu Art. 18 traz que "A organização políticoadministrativa da República Federativa do Brasil compreende a União, os Estados e os 209 
Municípios, todos autônomos, nos termos desta Constituição”.

Em seu Art. 60 que dispõe sobre emenda à Constituição, têm-se no parágrafo 4ํㅜㄴ "Não será objeto de deliberação a proposta de emenda tendente a abolir: I a forma federativa de Estado [...]". Face aos artigos constitucionais, nota-se que a estruturação federativa brasileira é efetivada sob o princípio da cooperação recíproca, sendo que, ao invés de um sistema dualista, hierárquico e/ou centralizado a Constituição delega competências e atribuições legislativas entre os integrantes do sistema federativo tendo em vista os limites expressos, de modo a reconhecer a dignidade e a autonomia própria dos entes subnacionais (CURY, 2006).

A disposição constitucional que reconhece os municípios como ente federativo, estabeleceu um regime normativo e político descentralizado e plural, no qual se cruzam novos e diferentes mecanismos de participação social que ampliam o número de sujeitos políticos aptos a tomar decisões. Assim, a cooperação exige um entendimento recíproco entre os entes federados e sua participação pressupõe a abertura de novas arenas públicas de deliberações e decisões (CURY, 2006).

Tendo em vista as desigualdades do país, cujas regiões são muito díspares entre si, têm-se alguns limites em relação à colaboração recíproca. O primeiro limite surge da omissão dos parlamentares em relação à elaboração da lei complementar exigida pela CRFB/1988 no Parágrafo Único do artigo 23 "Leis complementares fixarão normas para a cooperação entre a União e os Estados, o Distrito Federal e os Municípios, tendo em vista o equilíbrio do desenvolvimento e do bem-estar em âmbito nacional" (SOUZA, 2005; CURY, 2006).

Cumpre registrar, todavia, a complexidade da questão visto o reconhecimento do município como ente federativo, uma vez que tal conquista foi pouco absorvida pela maioria das municipalidades brasileiras que muitas vezes mantem forte dependência em relação a outros níveis de governo. Na verdade, o regime de colaboração apresenta-se como "um instituto relativamente fácil de proclamar, mas muito complexo de se debater teórica e juridicamente". (ARAÚJO, 2010, p. 754).

No decorrer dos anos de 1990 e com a centralidade do ajuste fiscal, a temática da municipalização ingressou na agenda com polêmicas devido às carências de muitas municipalidades no que diz respeito aos recursos humanos e financeiros e, sobretudo por um conflito federativo: a transferência de encargos sem a garantia das respectivas receitas. (MARTINS 2011).

Sobre isso, entende-se que os papéis desempenhados pelos entes federados devem assegurar o exercício da autonomia dos vários níveis de governo na definição das políticas educacionais sem, contudo, perder de vista a coordenação nacional. Uma vez que, nas últimas décadas, essas políticas têm procurado resgatar esse papel da União (CABRAL NETO, CASTRO, GARCIA, 2016).

1- Parágrafo Único com redação determinada pela Emenda Constitucional n. 53, de 19/12/2006. 
A implementação das políticas públicas educacionais dá-se no âmbito dos entes subnacionais e, dessa forma, não alcançarão seus fins se desconsiderarem as diferentes realidades e prescindirem da participação local. As discussões acerca do federalismo cooperativo brasileiro no tocante as políticas públicas sociais não podem desconsiderar que os conflitos federativos estão na sua base (ARAÚJO, 2010).

Essa discussão "diz respeito não só aos fundamentos do federalismo, como também à forma que este assumiu na história política brasileira, pois tem relação direta com as disputas entre o nacional e o local e os interesses das elites políticas em um ou outro desses vetores" (ARAÚJO, 2010, p. 750).

Essas disputas aliadas à falta de clareza sobre as matérias e competências concorrentes e comuns entre Estados e municípios, complexificam as relações e, por consequências, o alcance dos fins republicanos distanciam-se sobremaneira.

Com a complexidade de tais questões, os conflitos federativos assumiram duas dimensões: a) dimensão vertical traduzida por programas de descentralização por parte do governo federal que também se relaciona com a ação competitiva envolvendo estados e municípios na busca por recursos e; b) dimensão horizontal cuja guerra fiscal exemplifica os conflitos dada as dificuldades de articulação e coordenação do governo federal. (ARAÚJO, 2010).

Nesse complexo arcabouço institucional em que se situa as relações federativas, têm-se as relações sociais, cujas negociações e disputas permanentes refletem no planejamento das políticas públicas educacionais. O debate sobre o poder local nesse contexto, adquire contornos próprios na medida em que se aprofunda, segundo Vieira (2011), a lógica de pensar globalmente e agir localmente, uma vez que o Brasil tem incorporado elementos da agenda educacional global.

A tensão permanente entre poder central/poder local, característica da sociedade brasileira permanece nos diferentes contextos históricos, embora com os sentidos redimensionados.

Se considerarmos a natureza do Estado português e do processo de colonização aqui instalado, teremos elementos para visualizar como se forja a relação entre poder central e poder local no Brasil. A obra do Brasil Colônia tem a marca definidora da centralização. A simbiose colonizador-colonizado é complexa e comporta mediações não redutíveis a uma aproximação simples. Vale lembrar, entretanto, como tese geral, que, se a centralização é a tendência dominante das origens de nossa história, um movimento na direção contrária também se expressa como tendência dominada no cenário que vai se configurando na sociedade emergente (VIEIRA, 2011, p.28-29).

Torna-se necessário, portanto redimensionar as reflexões, uma vez que quando se reflete acerca do poder local, em geral, vislumbram-se espaços, órgãos, situações, cujos espaços decisórios aproximam-se dos sujeitos. Bairro, distrito e município, sob essa perspectiva, são instâncias de poder local, da mesma forma que a escola e demais espaços institucionais da gestão educacional. 
Município, poder local e planos municipais de educação...

O fato da expressão poder local remeter à existência de outras esferas de poder, como à noção de poder central, por oposição, não é uma questão trivial, visto que as reflexões sobre os temas remetem a conceitos teóricos que ultrapassam o campo da educação e desse estudo. No entanto, visto a permanente tensão entre local e central torna-se impossível ignorar esses dois polos que estão em movimento e, ora se complementam, ora se opõem.

A noção de poder local na história brasileira, como esclarece Vieira (2011), vinculase ao patrimonialismo e coronelismo no exercício do poder político. Tais fenômenos não se expressam somente na política local, mas tem a ver com a conexão entre município, estado e União, prefeitos, governadores e presidentes num jogo de coerção e cooptação (LEAL, 2012)

Contudo, sob circunstâncias democráticas advindas com a nova ordem constitucional, as reflexões acerca de nacional e local exigem novos olhares a fim de incorporar a participação da sociedade civil e dos movimentos sociais que ressignificam as formas de articulação, uma vez que o tema está sujeito a contradições. 0 reconhecimento do município como ente federativo requer novas aproximações acerca do papel das instâncias e sujeitos locais, sobretudo com o advento da legislação educacional posterior à promulgação da CRFB/1988, que delimita o papel do poder local em matéria educacional.

Embora o reconhecimento do município signifique uma certa autonomia, há um fortalecimento do poder central na definição das políticas educacionais, cujos programas e projetos podem desconsiderar as peculiaridades locais, desprestigiando regiões geográficas, sujeitos históricos, cenários urbanos e rurais, dentre outros aspectos.

A ação do governo central e a correlação de forças entre as unidades subnacionais
entre si e com a União devem convergir tanto no sentido da coordenação quanto
no sentido da colaboração federativa para a garantia da equalização num Estado
federativo de bases cooperativas [...] É preciso que se faça uma distinção entre
coordenação e colaboração federativa, pois ao passo que a primeira se constitui
em procedimento que busca resultado comum a partir do governo central, apesar
de autonomia dos entes federados, a colaboração federativa se traduz no modo de
atribuições e exercício das competências concorrentes e comuns, devendo a
tomada de decisões e o exercício das competências serem conjuntos e não
isolados (ARAÚJO, 2013, p. 790 -799).

A análise dos sentidos que as políticas educacionais tomam em âmbito municipal exige um constante esforço a fim de evitar, conforme alerta Gouveia (2008, p. 17), duas armadilhas: a primeira relacionada aos riscos de uma análise localista, cujo desenvolvimento das políticas educacionais seja visto como "fonte de virtude" e a segunda, por sua vez, refere-se ao "determinismo do geral sobre o local" onde o local é concebido, a priori, por seus vícios.

Isso requer uma análise detida e não simplificada das diferentes formas de manifestação do fenômeno educativo em âmbito local de modo a não reduzi-lo a um espaço, por excelência, palco de tradições patrimonialistas, cujas relações são determinadas com poucas possibilidades de intervenção e mudança social. 
O status auferido no contexto dos anos de 1980 aos municípios brasileiros difere dos demais textos e contextos constitucionais, haja vista as sucessivas alterações no que tange à sua posição no cenário federativo, como se demonstra no quadro a seguir:

Quadro 01: Município nas Constituições Federais do Brasil

\begin{tabular}{|c|c|}
\hline Constituição & Dispositivos sobre o Município \\
\hline $\begin{array}{l}\text { Constituição de } 1824 \\
\text { (Brasil Império) }\end{array}$ & $\begin{array}{l}\text { A Administração era centralizada e a Constituição do Império continha apenas } \\
\text { alguns artigos sobre as Cidades e as Vilas (não se utilizava a palavra Município). }\end{array}$ \\
\hline $\begin{array}{l}\text { Constituição de } 1891 \\
\text { (Brasil República) }\end{array}$ & $\begin{array}{l}\text { Contemplou referência ao Município, de forma indireta, ao determinar que os } \\
\text { Estados se organizassem de forma que assegurasse a autonomia do Município, } \\
\text { "em tudo quanto respeite ao seu peculiar interesse". }\end{array}$ \\
\hline $\begin{array}{l}\text { Constituição de } 1934 \\
\text { (Segunda República) }\end{array}$ & $\begin{array}{l}\text { Inovou em relação ao tratamento dado ao Município, que passou a ter sua auto- } \\
\text { nomia, naquilo que respeitasse ao seu peculiar interesse, reconhecida de forma } \\
\text { direta e explícita. Falou-se pela primeira vez em autonomia política (eleição de } \\
\text { seus Prefeitos e Vereadores), financeira (decretação de seus impostos, taxas e } \\
\text { outras rendas) e administrativa (organização de seus serviços), porém não Ihe } \\
\text { coube menção como ente constitutivo da Federação brasileira. }\end{array}$ \\
\hline $\begin{array}{l}\text { Constituição de } 1937 \\
\text { (Estado Novo) }\end{array}$ & $\begin{array}{l}\text { Manteve a condição anterior, pois também não incluiu o Município como compo- } \\
\text { nente da Federação, que ficou como nas duas Cartas anteriores. Permaneceu, } \\
\text { entretanto, o respeito à autonomia municipal, com seus desdobramentos. }\end{array}$ \\
\hline $\begin{array}{l}\text { Constituição de } 1946 \\
\text { (Redemocratização) }\end{array}$ & $\begin{array}{l}\text { A Federação permaneceu composta pelos Estados, Distrito Federal e Territó- } \\
\text { rios, sem incluir o Município, e a autonomia deste manteve-se compreendendo } \\
\text { aspectos políticos, administrativos e financeiros }\end{array}$ \\
\hline $\begin{array}{l}\text { Constituição de } 1967 \\
\text { (Regime Militar) }\end{array}$ & $\begin{array}{l}\text { Relativizou a autonomia municipal, especialmente no concernente à escolha } \\
\text { dos Prefeitos, que se poderia dar pelo voto popular, pelo Governador do Estado } \\
\text { (capitais e Municípios considerados estâncias hidrominerais) e pelo Presidente } \\
\text { da República (Municípios declarados de interesse da segurança nacional). A } \\
\text { Emenda Constitucional no } 1 \text {, de } 1969 \text {, manteve a competência estadual para } \\
\text { ditar a lei orgânica, repetiram-se as normas sobre autonomia financeira e admi- } \\
\text { nistrativa e mantiveram-se as limitações às eleições dos Prefeitos, o que mais } \\
\text { tarde veio a ser revogado por meio de emenda, estendendo-se as eleições a } \\
\text { todos os Municípios, sem exceção. }\end{array}$ \\
\hline $\begin{array}{l}\text { Constituição de } 1988 \\
\text { (Constituição Cidadã) }\end{array}$ & $\begin{array}{l}\text { A CRFB/1988 inseriu o Município expressamente em seu texto, evidenciando } \\
\text { a sua integração como ente federativo autônomo (arts. 10 da CRFB/1988). Em } \\
\text { face dessa situação e das prerrogativas municipais elencadas na CRFB/1988, } \\
\text { têm-se a autonomia política, administrativa e financeira, nos termos do art. } 18 \\
\text { da CRFB/1988. }\end{array}$ \\
\hline
\end{tabular}

Fonte: Elaboração própria com base em IBAM (2009).

Nos termos da CRFB/1988, têm-se, portanto, a autonomia do munícipio: a redação dos art. 29, 29-A e 30 da CRFB/1988 consagram a capacidade desse ente federativo elaborar sua lei orgânica e se responsabilizar por uma série de atribuições, dentre as quais está a de eleger seus agentes políticos, prestar serviços e administrar recursos, dentre outras coisas.

Da leitura do art. 18 da CRFB/1988 pode-se inferir que o Município dispõe de determinadas prerrogativas nas seguintes dimensões: a) política: eleição direta do Prefeito, do Vice-Prefeito e dos Vereadores. b) administrativa: organização dos serviços públicos de interesse local e elaboração da lei orgânica; c) financeira: instituição e arrecadação de tributos e aplicação de sua receita e; d) legislativa: competência para legislar sobre assuntos de interesse local de modo a suplementar a legislação federal e 
estadual no que lhe interessar e for possível, especialmente em relação a algumas matérias listadas no art. 24 da CRFB/1988.

O interesse local deve ser compreendido como aquele que seja predominantemente circunscrito ao âmbito municipal. Desse modo, as matérias que interessar ao município de modo predominante, em relação ao Estado (interesse regional) e à União (interesse nacional), será de competência legislativa municipal.

A autonomia dos municípios expressa no texto constitucional guarda contornos próprios e peculiares que exigem uma reflexão quanto aos condicionantes subjacentes à sua constituição e materialização.

As dimensões continentais do Estado brasileiro é um fenômeno que não se pode desconsiderar nas análises cujas relações federativas em geral e, em particular, o status do município estão em tela. Embora as disposições constitucionais consagrem os ideais de autonomia, esse fenômeno manifesta-se de diferentes modos, a depender do contexto social à em que se desenvolve.

\section{AUTONOMIA DOS MUNICÍPIOS EM MATÉRIA EDUCACIONAL}

Em especial ao contexto educativo, a CRFB/1988 sinaliza para a ideia de Sistema Municipal de Ensino ao estabelecer em seu artigo 211 que "A União, os Estados, o Distrito Federal e os Municípios organizarão, em regime de colaboração, os seus sistemas de ensino" (BRASIL, 1988). Para que um Sistema Municipal de Ensino se efetive, é necessário um órgão regulador, isto é, o Conselho Municipal de Educação com funções definidas e regulamentadas em lei.

Nos termos do art. 11 da LDBEN/1996, os Municípios incumbir-se-ão de organizar, manter e desenvolver seus sistemas de ensino, integrando-os às políticas e planos educacionais da União e dos Estados. Todavia, o parágrafo único do referido artigo possibilita ainda, caso não organizem sistema próprio, que os municípios optem por integrar-se ao sistema estadual de ensinou ou componham um sistema único de educação básica (BRASIL, 1996).

O município pode, portanto, decidir entre as seguintes possibilidades previstas em lei: a) instituir o próprio sistema de ensino; b) integrar-se ao sistema estadual de ensino; c) compor com o estado, no âmbito de seu território, um sistema único de educação básica.

Embora tenha passado mais de três décadas das disposições constitucionais acerca da criação de sistemas de ensino pelos municípios, as reflexões atinentes ao poder local, situadas no bojo dos planos de educação, exigem a compreensão da organização e funcionamento da gestão educacional, sobretudo no contexto dos municípios de pequeno porte.

De todo modo, a leitura que se extrai da figura acima, refere-se as possíveis formas de materialização da autonomia local do ponto de vista normativo, a partir dos dispositivos legais correlacionados mencionados.

Embora a CRFB/1988 e LDBEN/1996 possibilitem aos municípios decidirem pela 
constituição ou não de sistema próprio de ensino, a elaboração do Plano Municipal de Educação apresenta-se como determinação legal numa perspectiva dupla: primeiro, pois o município enquanto ente federativo goza de autonomia para legislar sobre matérias de interesse local, nos termos do art. 18 da CRFB/1988; segundo, devido ao fato de que os Planos Nacionais de Educação pós CRFB/1988 determinaram que os estados e municípios deveriam elaborar ou adequar seus respectivos planos decenais, articulados ao nacional, sem desrespeitar, todavia, suas peculiaridades.

Ao compreender que a constituição de um sistema próprio de ensino pelo município configura-se como um exercício da autonomia auferida-lhe historicamente, faz-se necessário reconhecer os desafios postos à materialização das competências de um sistema Municipal de Ensino, nos termos do art. 11 da LDBEN/1996 e respectivos órgãos.

Quadro 02: Atribuições - Sistema Municipal de Ensino e órgãos fundamentais.

\begin{tabular}{|c|c|c|c|}
\hline \multicolumn{4}{|c|}{$\begin{array}{l}\text { SISTEMA MUNICIPAL DE } \\
\text { ENSINO }\end{array}$} \\
\hline \multicolumn{4}{|c|}{$\begin{array}{c}\text { Atribuições } \\
\text { Art. } 11 \text { da LDBEN/1996 }\end{array}$} \\
\hline \multicolumn{4}{|c|}{$\begin{array}{l}\text { I. organizar, manter e desenvolver os órgãos e instituições oficiais dos seus sistemas de ensino, integran- } \\
\text { do-os às políticas e planos educacionais da União e dos Estados; } \\
\text { II. exercer ação redistributiva em relação às suas escolas; } \\
\text { III. baixar normas complementares para o seu sistema de ensino; } \\
\text { IV. autorizar, credenciar e supervisionar os estabelecimentos do seu sistema de ensino; } \\
\text { V. oferecer a educação infantil em creches e pré-escolas, e, com prioridade, o ensino fundamental, permitida } \\
\text { a atuação em outros níveis de ensino somente quando estiverem atendidas plenamente as necessidades } \\
\text { de sua área de competência e com recursos acima dos percentuais mínimos vinculados pela Constituição } \\
\text { Federal à manutenção e desenvolvimento do ensino. }\end{array}$} \\
\hline \multicolumn{4}{|c|}{ ORGÃOS DO SISTEMA } \\
\hline Secretaria Municipal de Educação & Cons & oo Municipal d & Icação \\
\hline Executivo & Normativo & Deliberativo & Consultivo \\
\hline Atribuições* & \multicolumn{3}{|c|}{ Atribuições* } \\
\hline $\begin{array}{l}\text { I. Garantir educação básica obrigatória e gratuita na } \\
\text { educação infantil e no ensino fundamental à todas as } \\
\text { crianças do município; } \\
\text { II. Prestar atendimento educacional especializado às } \\
\text { pessoas com deficiência, preferencialmente na rede } \\
\text { regular de ensino; } \\
\text { III. Atender os alunos por meio de programas suple- } \\
\text { mentatres de material didático escolar, transporte e } \\
\text { alimentação; } \\
\text { IV. Garantir padrões mínimos de qualidade do ensino; } \\
\text { V; Organizar, manter e desenvolver órgãos e institui- } \\
\text { ções oficiais do Sistema Municipal de Ensino; } \\
\text { VI. Exercer ação distributiva em relação às escolas do } \\
\text { Sistema Municipal; } \\
\text { VII. Autorizar, credenciair e supervisonar os estabe- } \\
\text { lecmentos do seu Sistema de Ensino, atendendo as } \\
\text { normas complementares expedidas pelo Conselho } \\
\text { Municipal de Educação, dentre outras atribuições. }\end{array}$ & $\begin{array}{l}\text { I. Fixar diretriz } \\
\text { municipal de e } \\
\text { municipais; } \\
\text { II. Colaborar c } \\
\text { maulação da p } \\
\text { nicipal de edu } \\
\text { III. Zelar pelo } \\
\text { titucionais, e } \\
\text { cacional; } \\
\text { IV. Assistir e or } \\
\text { ção dos assun } \\
\text { V. Propor norn } \\
\text { cos em educa } \\
\text { VI. Autorizar } \\
\text { estabelecimen } \\
\text { competência } \\
\text { credenciamen } \\
\text { VII. Propor me } \\
\text { que tange a e } \\
\text { dades em rel } \\
\text { fun- damental. }\end{array}$ & $\begin{array}{l}\text { Spara a aorga } \\
\text { ino ou para o } \\
\text { n o poder púb } \\
\text { ítica e na elab } \\
\text { ção; } \\
\text { Imprimento da } \\
\text { mais normativ } \\
\text { ntar os podere } \\
\text { s educacionai } \\
\text { s para aplicaç } \\
\text { o no municípic } \\
\text { o fun } \\
\text { s de ensino } \\
\text { e editar } \\
\text { supervisão e } \\
\text { das ao poder } \\
\text { iva assunção } \\
\text { ão à educaç }\end{array}$ & $\begin{array}{l}\text { ção do sistema } \\
\text { Into das escolas } \\
\text { hunicipal na for- } \\
\text { ăo do plano mu- } \\
\text { posições cons- } \\
\text { m matéria edu- } \\
\text { licos na condu- } \\
\text { município; } \\
\text { e recursospúbli- } \\
\text { mento de } \\
\text { âmbito de sua } \\
\text { ormas para } \\
\text { e- ção. } \\
\text { co municipal no } \\
\text { uas resposabili- } \\
\text { ffantil e ensino }\end{array}$ \\
\hline
\end{tabular}

Fonte: Elaboração própria com base em BRASIL (2018)

*As atribuições apresentadas são demonstrativas visto as muitas outras que os respectivos órgãos podem exercer. 215 
Decorridos mais de três décadas da promulgação da CRFB/1988 e abertura aos municípios de constituírem-se enquanto sistemas, aí compreendidos a existência de unidades escolares, Secretaria Municipal de Educação e Conselho Municipal de Educação, observa-se, um número considerável de constituição de conselhos de educação e, desse modo, de sistemas.

Tabela 01: Quadro geral dos Conselhos e Sistemas Municipais de Ensino

\begin{tabular}{|c|c|c|c|}
\hline Unidade da Federação & Total de municípios & Municípios com CME & $\%$ \\
\hline União & 5.570 & 5.167 & $92 \%$ \\
\hline
\end{tabular}

Fonte: Elaboração própria com base em Pesquisa de Informações Básicas Municipais - MUNIC, 2018.

A constituição de um Sistema Municipal de Ensino não pode reduzir-se a tão somente a criação de uma lei, sem que haja, necessariamente, a reflexão coletiva acerca dos condicionantes e enfrentamentos subjacentes a tal constituição. Trata-se, portanto, de sistematizar atos intencionais, cuja organicidade e articulação das partes (Unidades Escolares + Secretaria Municipal de Educação + Conselho Municipal de Educação) constituam-se em unidade. "[...] Sistematizar, portanto, é dar, intencionalmente, unidade à multiplicidade, cujo resultado se chama sistema" (SAVIANI, 1983, p. 72).

Essas considerações visam demonstrar a importância e a complexidade em que se situa a gestão educacional nos municípios, cuja manifestação pode interferir nas ações relativas à constituição de um Sistema Municipal de Ensino.

Analisada no contexto do planejamento educacional em âmbito local, cujas prioridades estão elencadas nos Planos Municipal de Educação, a ordenação de despesas e a constituição de sistema próprio de educação não se reduz apenas a tomada de decisão sobre a alocação de recursos. Diz respeito aos esforços e intencionalidades com vistas a criar as condições necessárias para materializar os direitos disputados, defendidos e elencados no texto das leis que aprovaram os respectivos planos decenais de educação.

A LDBEN n 9.394/96 prevê em seu artigo 15 que "Os sistemas de ensino assegurarão às unidades escolares públicas de educação básica que os integram progressivos graus de autonomia pedagógica e administrativa e de gestão financeira, observadas as normas gerais de direito financeiro público". De tal modo, a autonomia na administração dos recursos financeiros em âmbito local, contemplada na legislação coloca-se comomeio para materializar a gestão democrática.

Desse modo, cumpre registrar as disputas em torno do poder de agenda e de investimento no âmbito das Secretarias Municipais de Educação, cujo instituto da ordenação de despesas pode recair, ainda que sob outras condições, em outros cargos que desempenharão a função e não necessariamente nos secretários de educação dos municípios.

Nos termos do Tesouro Nacional, considera-se ordenador de despesa qualquer 
autoridade de cujos atos resultem emissão de empenho, autorização de pagamento, suprimento ou dispêndio de recursos da União, estados e municípios. O ordenador de despesas detém de competência para emissão de notas de empenho e autorização para liquidação de despesas, tendo o dever de prestar contas.

A configuração dos ordenadores de despesa atinentes aos recursos da educação delineia-se de modo variável, embora com muitas similaridades. Em contexto nacional, Prefeitos e Secretários Municipais de Educação são os principais ordenadores, embora àquele ainda seja em maior número ${ }^{2}$. Se os dados forem agrupados em apenas dois grupos (Secretária Municipal de Educação e outros), observar-se-á que os outros são a grande maioria no tocante à ordenação das despesas da educação, correspondendo a 3.160 municípios brasileiros $-54,74 \%$, como se observa na figura que segue:

Figura 02: Ordenador de despesa da educação nos municípios brasileiros

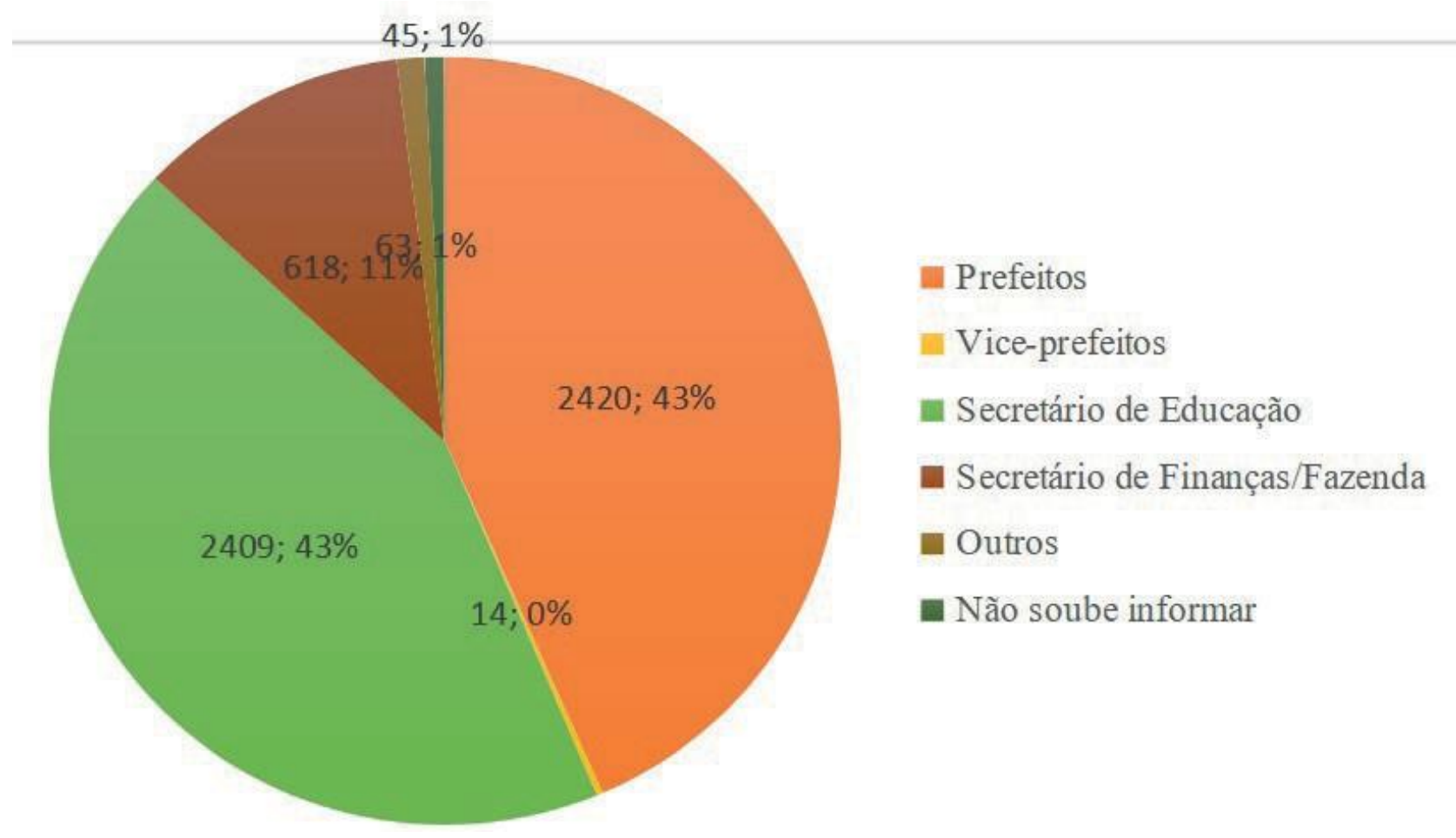

Fonte: Elaboração própria com base em Pesquisa de Informações Básicas Municipais - MUNIC, 2018.

A configuração dos dados acerca da ordenação de despesas é importante quando se concebe a autonomia administrativa e financeira dos recursos em âmbito local. Além disso, é comum os argumentos de que os recursos direcionados à educação não são sufi cientes ou utilizados de maneira coerente, carecendo de fiscalização e controle que viabilize a sociedade uma clara visão da origem e destino desses recursos.

2 É importante considerar outras possibilidades de leitura dessa informação, visto que 45 municípios não souberam informar quem era o responsável pela ordenação das despesas da educação no município. 
Município, poder local e planos municipais de educação...

Os dados acima evidenciam que em contexto nacional há muitos enfrentamentos no tocante à garantia de que os gestores educacionais sejam de fato os legitimados a administrar os recursos relativos aos investimentos em educação.

Ainda no tocante aos recursos em âmbito local, a partir da promulgação da CRFB/1988, segundo Amorim Neto e Simonassi, (2013) é possível dividir as transferências de recursos em dois grupos conforme sua natureza jurídica: a) transferências constitucionais: estão previstas de modo expresso na CRFB/1988 as quais obrigam os entes fede- rados a repasses parciais de alguns tributos, que são arrecadados pelo governo federal e transferidos aos estados e municípios por meio dos seus respectivos fundos de participação e; b) transferências voluntárias: compreendem os recursos financeiros repassados pela União aos estados e municípios em decorrência de acordos, convênios, ajustes ou outros instrumentos similares.

Em cumprimento aos dispositivos constitucionais, cabe ao Tesouro Nacional, efetuar as transferências desses recursos aos entes federados, cujas principais transferências da União para os Estados, o DF e os Municípios, previstas na CRFB/1988, são: Fundo de Participação dos Estados e do Distrito Federal (FPE); Fundo de Participação dos Municípios (FPM); Fundo de Compensação pela Exportação de Produtos Industrializados (FPEX); Fundo de Manutenção e Desenvolvimento da Educação Básica e de Valorização dos Pro- fissionais da Educação - (FUNDEB); e o Imposto sobre a Propriedade Territorial Rural - ITR (AMORIM NETO, SIMONASSI, 2013).

De um modo geral, as transferências de recursos são indispensáveis aos governos locais e, por consequência, não se pode desconsiderar sua natureza política. As transferências voluntárias, podem servir como barganhas políticas na medida em que se deixa de transferir recursos a determinadas localidades que precisam sobremaneira para alocá-los a outras, cuja visibilidade eleitoral é maior, seja do ponto de vista do número de eleitores com também das alianças partidárias.

Os presidentes brasileiros contam com considerável poder sobre a execução de recursos de transferências e usam estes recursos para superar o desafio de preservar sua coalizão de sustentação parlamentar. Para tanto, canalizam os recursos de que dispõem para os estados que contam com maior número de parlamentares na coalizão. Os parlamentes, por sua vez, têm fortes incentivos para integrar a coalizão de governo, pois daí deriva a credibilidade de que seus estados e municípios de ori- gem receberão recursos adicionais. Essa estratégia revela que os acordos entre os presidentes e o parlamento tendem a ser de longo prazo, e não aleatórios, em torno de cada votação legislativa (ARRETCHE, RODDEN, 2004, p.570).

Essas questões merecem destaque na medida em que as disparidades regionais, característica de um país com dimensões continentais como o Brasil, poderiam ser minimizadas caso os recursos financeiros, sobretudo os advindos das transferências, fossem alocados com vistas a um equilíbrio financeiro nas economias subnacionais.

Interessante observar que o regime federativo pressupõe colaboração entre os entes subnacionais com vistas ao alcance dos princípios republicanos, o que requer, indubita- velmente, a universalização da educação pública e seu constante aprimoramento. 
Todavia, esse complexo bojo de transferências negociadas e fundos de participação, aliados as verbas vinculadas a programas e projetos do governo federal, complexificam as relações em âmbito local e sinalizam dimensões da centralização dos recursos financeiros no âmbito da União.

Abrucio (2010) chama a atenção para a importância dada aos governos subnacionais na década de 1980 visto que os poderes locais são a maior referência estatal na execução das políticas públicas sociais. No entanto, mesmo com a complexificação das rela- ções sociais em âmbito local, o autor destaca que a literatura parte da hipótese de que os governos subnacionais são marcados pelo atraso histórico da modernização da máquina pública em detrimento de estudos acerca das mudanças efetivas ocorridas nos Estados e municípios brasileiros no contexto da redemocratização do país.

Sobre isso Arretche (2010) argumenta que as relações entre a União e os entes subnacionais precisam ser analisadas a luz das desigualdades territoriais, visto que a história do Brasil é marcada por jurisdições ricas e pobres. Esse contorno, alia-se a possibilidade de que a descentralização da execução de políticas públicas seja compatível com a centraliza- ção da autoridade, mesmo sob a denominação de um Estado federativo. Por consequência, a análise sobre as realidades dos municípios não deve desconsiderar, portanto, as relações central/local.

Em âmbito local, a questão financeira apresenta-se com uma dimensão crítica nos municípios com até 50 mil habitantes (89\% do total de municípios brasileiros e $36 \%$ da população nacional), nos quais os "gastos com educação, cultura, saúde e saneamento básico já respondem por $54 \%$ da sua receita bruta (e cerca de $70 \%$ da sua receita líquida de impostos" (PINTO, 2014, p.630).

[...] historicamente Estados e municípios assumiram a execução da educação básica de forma descentralizada, o que reproduziu as desigualdades regionais, pois Estados e municípios com mais recursos financeiros e com quadros capacitados para a elaboração de políticas tinham formas muito diversas de oferta e qualidade do que aqueles sem as mesmas condições. (FERNANDES, BRITO, PERONI, 2012, p.571).

Diante dessas questões, não se pode desconsiderar os enfrentamentos e os modos sob os quais a autonomia administrativa e financeira dos municípios se configura, nesse complexo emaranhado de relações políticas e sociais num pais com dimensões continentais como o Brasil. Pensar os instrumentos viabilizadores da gestão democrática em âmbito local exige, portanto, compreender as relações e os demais condicionantes sociais e econômicos presentes nas relações educativas materializadas no cotidiano dos municípios.

É no contexto das relações federativas, da autonomia e do poder local que os Planos Municipais de Educação estão situados. Desse modo, se o Plano Nacional de Educação deve ser o epicentro das políticas educacionais, por lógica, resguardadas as regras de competência dos entes subnacionais, o Plano Municipal de Educação deve ser o epicentro 
das políticas educacionais locais, cuja materialização pode expressar ou apresentar-se como um exercício da autonomia do município e do poder local, nos termos das CRFB/1988.

Essas considerações preliminares acerca de alguns dos diversos condicionantes em que o governo e suas ações se forjam são necessárias a fim de situar o cenário em que os planos decenais de educação estão situados. Por certo, a formulação da política de educação nos municípios não se limita a essas questões, mas não se pode desconsiderar que as intermitências de ordem político partidárias afetam os rumos e prioridades educacionais no país, especialmente no tocante aos planos decenais de educação e suas metas e estratégias elencadas como prioritárias.

Em especial às atribuições dos municípios, constitua ele ou não ou Sistema Municipal de Ensino, há diversas responsabilidades no tocante à sua competência em matéria educacional que podem, sinteticamente, agruparem-se em duas dimensões. Uma referente ao pedagógico, isto é, as ações necessárias para organização e execução do trabalho pedagógico na secretaria e escolas, aí envolvidos a elaboração da proposta pedagógica da rede municipal e respectivos Projetos Políticos Pedagógicos das escolas, o desenvolvimento da gestão democrática, formação de professores, acompanhamento dos processos avaliativos internos e externos, dentre outros.

Outra, referente à dimensão administrativo-financeira que envolve: a) a gestão de pessoas e atividades correlatas, envolvidas as contratações, licenças, dentre outras temáticas relativas aos trabalhadores em educação e demais sujeitos individuais e coletivos que se envolvem no processo educativo); b) execução financeira, relacionadas as fontes de recursos destinadas ao financiamento da educação pública e demais atividades ligadas à gestão de materiais e patrimônio com vistas manutenção e desenvolvimento do ensino.

A dimensão administrativo-financeira implica considerar as disputas em torno do financiamento público em educação, especialmente no que tange a materialização dos direitos à e na educação, situados no bojo das metas e estratégias definidas para a educação do decênio. Desse modo, as prerrogativas funcionais da Secretaria Municipal de Educação em relação a manutenção e desenvolvimento do ensino não podem ser desconsideradas, sob pena de amenizar e/ou desconsiderar as implicações decorrentes do bojo político-partidário na composição das pastas e execução das atividades atinentes ao ensino.

No cerne das disputas entre os poderes, o Executivo não deve ser percebido como elo fraco no bojo das articulações políticas, uma vez que ele controla os recursos, obras e afins que são almejados pelos parlamentares, sobretudo com vistas à reeleição. Além disso, a formação do governo, envolvida a distribuição de secretarias municipais e nomeações nos outros cargos comissionados, guarda relação com a coalização partidária que possibilita ao Executivo aprovar suas matérias na Câmara Municipal.

As articulações políticas pressupõem, portanto, consistências formais entre os Poderes, principalmente nas votações das propostas governamentais, uma vez que a 
caneta que nomeia à determinado cargo é a mesma que demite e isso afeta diretamente os corre- ligionários e, por consequência os interesses dos parlamentares.

Sob esse ponto de vista, a gestão dos recursos financeiros em geral e, em particular, a ordenação de despesas na pasta da educação nos municípios não significa apenas ordenar, no sentido literal, de modo a autorizar o pagamento e/ou contratação de produtos e serviços circunscritos à sua competência. Trata-se, principalmente, de viabilizar o funcionamento, a manutenção e o progressivo investimento público em educação.

Todavia, embora com ressalvas, a composição e ocupação dos altos cargos de uma Prefeitura Municipal não observa, necessariamente, aspectos relacionados a experiência e competência acadêmico-profissional dos candidatos com vistas a consecução das ações. Desse modo, pode haver Secretários Municipais de Educação, cuja finalidade não seja, em primeiro lugar, garantir à materialização dos direitos à e na educação, mas, tão somente garantir as bases necessárias com vistas à determinados benefícios e finalidades político-eleitorais.

Dentre as diversas responsabilidades no tocante à gestão educacional, a LDBEN/1996 em seu art. 69 evidencia os mínimos constitucionais que os entes federados deverão investir na manutenção e desenvolvimento do ensino público, sendo determinado aos municípios o percentual de $25 \%$ (vinte e cinco). O $\S 5^{\circ}$ traz que o repasse dos valores referidos no artigo 69 do caixa da União, dos Estados, do Distrito Federal e dos Municípios ocorrerá imediatamente ao órgão responsável pela educação.

Se não bastasse a complexidade apresentada nos parágrafos acima, há que destacar o momento atual de 2020 em que no bojo das contrarreformas, têm-se em curso o Projeto de Emenda à Constituição no 188/2019 (BRASIL, 2019) em que um de seus objetivos é a extinção dos municípios com arrecadação dos impostos municipais Imposto sobre Serviços (ISS), Imposto Predial e Territorial Urbano (IPTU) e Imposto de Transmissão de Bens Imóveis (ITBI) - maior que 10\% sobre o total da receita e com população menor que 5.000 habitantes.

A principal justificativa para a apresentação da PEC é que esta reduziria o tamanho da máquina pública, melhoraria a eficiência dos municípios, além de diminuir os custos com estruturas administrativas e as despesas com os Legislativos Municipais. Dos 5.568 Municípios brasileiros, 4.585 (82\%) ficaram abaixo do mínimo de 10\% de arrecadação própria. 1.252 municípios, ou seja, 22,5\% do total do país, têm menos de 5 mil habitantes. Destes, 1.217 (97\%) não atingem o mínimo de 10\% dos impostos sobre suas receitas totais. 4.096.247 habitantes vivem nos Municípios que seriam extintos (CNM, 2019).

Caso aprovada nos moldes apresentados, os municípios terão até 30 de junho de 2023 para comprovar sua sustentabilidade financeira. O município extinto, por sua vez, será incorporado a partir de 2025 ao município limítrofe com melhor sustentabilidade financeira, observado o limite de até três municípios por um único incorporador.

Ora, percebe-se que a proposta em curso desconsidera veementemente o pleno funcionamento das instituições e das pessoas que possuem histórias, patrimônio cultural e 
religioso nesses municípios em via de extinção. Os critérios objetivos apresentados não detém de justificativas de viabilidade social, econômica e política na medida em que desconsidera o anseio da população dos municípios, além da violação constitucional procedimental, pois a incorporação dos municípios só pode ocorrer na forma do art. 18, $\S 4^{\circ}$, da Carta Política. Por fim, há evidente ultraje, contra a cláusula pétrea do federalismo, insculpida no art. $60, \S 4^{\circ}$, I da CRFB/1988.

É fundamental que o pacto federativo seja repensado, mas é um equívoco relacionar, única e exclusivamente os parâmetros de eficiência administrativa com tamanho dos municípios e arrecadação própria uma vez que na composição total das receitas se somam as transferências federais e estaduais variadas.

A PEC 188/2019 também deixa no "limbo" a repartição do Fundo de Participação dos Municípios (FPM) após a absorção de um município extinto por outro nem considerada a viabilidade da união de dois municípios com núcleos urbanos com centenas de quilômetros de distância. A oferta e manutenção dos serviços públicos nessas condições poderá acarretar, de certo modo, o aumento dos custos.

Todo este cenário evidencia as contradições no tocante à materialização dos alicerces estabelecidos pela CRFB/1988 na medida em que rompe e inviabiliza a lógica cooperativa entre os entes subnacionais, de modo a esfacelar o regime de colaboração e a busca pela superação dos desequilíbrios regionais, tão evidentes no cenário brasileiro.

\section{CONSIDERAÇÕES FINAIS}

A disposição constitucional que reconhece os municípios como ente federativo, estabeleceu um regime normativo e político descentralizado que amplia o número de sujeitos políticos aptos a participar. Todavia, deve-se considerar a complexidade da questão visto que a maioria das municipalidades ainda mantem forte dependência em relação a outros níveis de governo.

O reconhecimento do município como ente federativo requer novas aproximações acerca do papel das instâncias e sujeitos locais, sobretudo com o advento da legislação educacional posterior à promulgação da CRFB/1988, que delimita o papel do poder local em matéria educacional.

Embora a CRFB/1988 e LDBEN/1996 possibilitem aos municípios decidirem pela constituição ou não de sistema próprio de ensino, a elaboração do Plano Municipal de Educação apresenta-se como determinação legal. Enquanto o Plano Nacional de Educação deve ser o epicentro das políticas educacionais, por lógica, resguardadas as regras de competência dos entes subnacionais, o Plano Municipal de Educação deve ser o epicentro das políticas educacionais locais.

Diante dessas questões, não se pode desconsiderar os enfrentamentos e os modos sob os quais a autonomia dos municípios se configura, nesse complexo emaranhado de relações políticas e sociais num pais com dimensões continentais como o Brasil. 
Em contexto mais recente, as práticas de planejamento educacional em geral, e nos municípios em particular, intensificam-se na primeira década dos anos 2000, sob coordenação da União, a fim de dar organicidade às ações nos diferentes âmbitos, sem desconsi- derar, todavia, suas particularidades. O planejamento educacional no contexto dos planos municipais de educação apresenta-se, portanto, como uma prática social, cuja operacionalização pode envolver a comunidade local conferindo a esse processo historicamente técnico-burocrático - dinâmicas coletivas que estimulem a democracia.

A disposição constitucional que reconhece os municípios como ente federativo, estabeleceu um regime normativo e político descentralizado que amplia o número de sujeitos políticos aptos a participar. Todavia, deve-se considerar a complexidade da questão visto que a maioria das municipalidades ainda mantem forte dependência em relação a outros níveis de governo (ABRUCIO, 2010). 


\section{REFERÊNCIAS}

ABRUCIO, Fernando Luiz. A dinâmica federativa da educação brasileira: diagnóstico e propostas de aperfeiçoamento. In: OLIVEIRA, Romualdo Portela; SANTANA, Wagner. (Orgs.) Educação e federalismo no Brasil: combater as desigualdades, garantir a diversidade. Brasília, DF: UNESCO, 2010. Disponível em:

$<$ http://unesdoc.unesco.org/images/001,8/001873/187336por.pdf>. Acesso em: 10 out. 2015.

AMORIM NETO, Octávio; SIMONASSI, Andrei Gomes. Bases políticas das transferências intergo- vernamentais no Brasil (1985-2004). Revista de Economia Política. Vol.33, no 4.p. 704-725, out. Dez. 2013. Disponível em:

<http://www.scielo.br/pdf/rep/v33n4/v33n4a10.pdf>. Acesso em: 15 jan. 2019.

ARAÚJO, Gilda Cardoso. Constituição, federação e propostas para o novo plano nacional de edu- cação: análise das propostas de organização nacional da educação brasileira a partir do regime de colaboração. Educação e Sociedade. Campinas, v. 31, n. 112, p. 749768, jul.-set. 2010.

ARAÚJO, Gilda Cardoso. Federalismo e políticas educacionais no Brasil: equalização e atuação do empresariado como projetos em disputa para a regulamentação do regime de colaboração. Educa- ção e Sociedade. Campinas v. 34, n. 124, p. 787-802, jul.-set. 2013.

ARRETCHE, Marta Teresa da Silva. RODDEN, Jonathan. Política distributiva na federação: es- tratégias eleitorais, barganhas legislativas e coalizões de governo. Revista de Ciências Sociais, Rio de Janeiro, Vol.47, n.3, 2004,p.549-576. Disponível em: http://www.scielo.br/pdf/dados/v47n3/ a04v47n3.pdf. Acesso em: 15 de jan. 2019.

ARRETCHE, Marta Teresa da Silva. Federalismo e igualdade territorial: uma contradição em ter-

mos? Revista de Ciências Sociais, Rio de Janeiro, vol.53, no3, 2010, pp.587-620.

Disponível em:

<http://www.ocpf.org.br/wp-content/uploads/2014/11/Federalismo-e-lgualdade-TerritorialUma-Con- tradicao-em-Termos.pdf>. Acesso em: 15 de jan. 2019.

BRASIL. Constituição da República Federativa do Brasil de 1988. Brasília, DF, Presidência da República: 1988.

BRASIL. Lei de Diretrizes e Bases da Educação Nacional. Brasília, DF, Presidência da Repúbli- ca: 1996.

BRASIL. Senado Federal. Proposta de Emenda à Constituição n 188, de 2019. 2019. Dispo- nível em: <https://www25.senado.leg.br/web/atividade/materias/-/materia/139704>. Acesso em: 22 de set. 2020.

BRAVO, R. S. Técnicas de investigação social: Teoria e ejercicios. 7 ed. Ver. Madrid: Paraninfo, 1991.

CABRAL NETO, Antônio; CASTRO, Alda Maria Duarte Araujo; GARCIA, Luciane Terra dos San- tos. Plano municipal de educação: elaboração, acompanhamento e avaliação no 
contexto do PAR. Revista Brasileira de Políticas e Administração da Educação. V.32, n.1, p.47-67. jan/abr. 2016.

CNM. Confederação Nacional dos Municípios. Distribuição das transferências acumuladas. Dis- ponível em: <https://www.cnm.org.br/municipios/transferencias>. Acesso em: 11 de jan. 2019.

CURY, Carlos Roberto Jamil. Sistema Nacional de Educação: desafios para uma educação igualitá- ria e federativa. Educação e Sociedade. Vol. 29, N. 105, P.1187-1209. Set./out. 2008.

FERNANDES, Maria Dilnéia Espíndola; BRITO, Silvia Helena Andrade de; PERONI, Vera Maria Vidal. Sistema e Plano Nacional de Educação: notas sobre conceituação, relação público-privado e financia- mento. Revista brasileira de estudos pedagógicos. Vol. 93, n. 235. Braísila. Spt/dec. 2012. Dispo- nível em: < https://www.scielo.br/scielo.php?script=sci_arttext\&pid=S2176-66812012000400002>. Acesso em: 22 de set. 2020

INSTITUTO BRASILEIRO DE ADMINISTRAÇÃO MUNICIPAL. Manual do Prefeito. 13ำ edição.

209. Disponível em: < http://www.ibam.org.br/media/arquivos/estudos/manual_prefeito.pdf>. Aces- so em: 08 set. 2020.

LEAL, Victor Nunes. Coronelismo, enxada e voto: o município e o regime representativo no Brasil. 7.ed. Companha das Letras, São Paulo, SP. 2012.

MARTINS, Angela Maria; PIMENTA, Cláudia Oliveira. Planos Municipais de Educação de re- giões metropolitanas em São Paulo: análise de fontes oficiais. Fundação Carlos Chagas. 2011.

MUNIC. Pesquisa de Informações Básicas Municipais. 2018. Disponível em: $<$ https://www.ibge. gov.br/estatisticas/sociais/protecao-social/10586-pesquisadeinformacoes-basicas-municipais.ht- $\mathrm{ml} ?=\& \mathrm{t}=$ resultados $>$. Acesso em: 20 de maio de 2020.

PINTO, José Marcelino Rezende. Federalismo, descentralização e planejamento da educação: desafios aos municípios. Cadernos de Pesquisa. 2014, vol.44, n.153, pp.624-644. Disponível em: <http:// www.scielo.br/scielo.php?pid=S010015742014000300008\&script=sci_abstract\&tIng=pt>. Acesso em: 25 de abril de 2018.

SAVIANI, Dermeval. Escola e democracia: teorias da educação, curvatura da vara, onze teses so- bre a educação política. 41. ed. revista. Campinas, SP: Autores Associados, [1983] 2009.

VIEIRA, Sofia Lerche. Poder local e educação no Brasil: dimensões e tensões. Revista Brasileira de Políticas e Administração da Educação. V.27, n.1, p.123-133. Jan./abr.2011. 